\title{
Study on the National Integration in Chinese History
}

\author{
Yang Min $^{1}$ \\ ${ }^{1}$ Weinan Normal University, Weinan, Shaanxi, 714099
}

Keywords: Chinese history; Chinese Nation; national integration

\begin{abstract}
A nation is a community of people with common language, living in common areas, having common economic life and showing common cultural and psychological qualities. In the course of world economic development, the harmonious co-prosperity among different ethnic groups and the regional alliance are the inevitable trends in promoting the development of all ethnic groups in the world. In particular, for China with a vast territory and a large number of ethnic groups, the integration of various ethnic groups and regions is the important driving force of regional culture and of economic development. Although the current national policies in our country promote the integration and unity among different ethnic groups, there are still some contradictions, disputes and studies among different ethnic groups under the influence of different cultures, living habits and historical development. The national integration in Chinese history can achieve the true psychological harmony between different ethnic groups so as to promote the common prosperity and development among all ethnic groups. This paper expounds the concrete connotation of national integration, analyzes the types of national integration in Chinese history, and summarizes the characteristics of integration of the Chinese nation in order to provide reference for the integration and common prosperity of all ethnic groups in modern China.
\end{abstract}

\section{The Meaning of National Integration}

The integration of ethnic groups is a common phenomenon in multi-ethnic countries and an inevitable trend of historical development. The development and changes in the formation, formation and evolution of ethnic communities at all times and in all countries are closely related to the national integration. The concept of national integration can be understood as two levels. [1] One aspect refers to the integration of nationalities as a universal historical phenomenon. It means that two or more ethnic groups in history, as a result of their proximity to each other and their mutual influence, eventually form a nation. The national integration based on this concept is a universal phenomenon in multi-ethnic countries and also an inevitable trend of historical development. On the other hand, ethnic integration means that after the establishment of a communist society in the world, we have weakened the ethnic characteristics and ethnic differences and gradually formed human boundaries, the whole of humankind mainly expresses the ways and means of extinction of the global nation. [2] This study is based on the first level to study the issue of national integration. To some extent, ethnic integration is a kind of progress in the history of ancient China. It is precisely because of national integration that economic and cultural exchanges and exchanges among all ethnic groups in our country are promoted and that there is a common ground of common language, common economic life, common psychological quality and stability of the Chinese nation.

\section{The Type of National Integration in Chinese History}

The history of the development of the Chinese nation is a process of continuous interaction and continuous integration. [3] The integration of the Han nationality with the ancient ethnic minorities and the analysis of the history of ancient China show that the integration types of various nationalities in China include the integration of ethnic minorities into the Han nationality, the integration of the Han nationality into the ethnic minorities and the ethnic minorities The integration of each other. 


\subsection{Minorities into the Han}

The integration of ethnic minorities into the Han is the most common type of ethnic integration. At present, the Han population is the most populous nation in the world. The current population is not due to the simple natural population growth but to a large extent due to the integration of the ethnic minorities into the Han nationality. [4] However, there are mainly two ways for ethnic minorities to integrate into the Han nationality. One is that the ethnic minorities moved into the Han nationality and the Han nationality formed in the Han Dynasty. Due to their high level of Han culture, ethnic minorities are more and more integrated into the Han people, especially the Central Plains Region, it can be said that almost all the ethnic minorities entering the Central Plains were merged. The other is that the Han people moved into the minority areas in the border areas. The main methods include the Han rulers sending troops, immigrants entering ethnic minority areas and refugees entering a few areas. For example, after Qin Shihuang unified China, all ethnic groups in Nanban, Baiyue, Dongyi and other ethnic groups were all ruled by Qin State. Cantonese was the integration of Central Plains Mandarin with Baiyue in Qin and Han dynasties. [4] In short, since the formation of the Han nationality, it has frequently collided with and exchanged ideas with various ethnic groups in the surrounding areas in various ways, including war, migration and trade, and constantly absorbed new blood into its own nation and eventually developed into the largest ethnic group in the world. As a result, Han people and ethnic minorities have unsolved problems of kinship.

\subsection{The ethnic Han nationality}

Although the integration of ethnic groups in our history is mostly the integration of ethnic minorities into the Han nationality, there are also some Han nationalities that have merged with the ethnic minorities for many reasons, mainly due to a variety of reasons that have changed the objective environment. As a result, a small number of Han Chinese, in order to adapt themselves to the living conditions of ethnic minorities, Give up your own language and lifestyle. Specifically, the main reasons for the integration of Han into the ethnic minorities include the following aspects: Firstly, Chinese slaves are integrated into the slave nation. Before the Qing Dynasty, the northwestern nomads often waged war and clashes with the farming peoples in the north. The nomadic hermites invaded the Central Plains, not only plundering their property and land, but also many Han nationals being looted by ethnic minorities to become slaves. These captive slaves only entered the slave nation. [6] In order to survive better, so forced to integrate into the ethnic minorities. Second, refugees and immigrants are integrated into the local ethnic minorities. The integration of refugees and immigrants into the local ethnic minorities mainly resulted from the war-torn and famine migration to the ethnic Han people in the surrounding ethnic areas. These people also had the phenomenon of integration with ethnic minorities in the area. For example, during the Qin and Han Dynasties, the Central Plains war and many Han people would flee to the nomadic areas of the Huns. In the Western Han Dynasty, they should also strongly oppose striking and wrecking the Great Wall. At that time, the Han people volunteered to flee into the nomadic areas of the Huns. Thirdly, since the Western Han dynasty, in order to occupy more territory, most of the dynasties sent large numbers of Han Chinese to the western border and Tuntian.[6] These sent Han Chinese lived long-term lives in the ethnic minorities In the course of time, they will be integrated into these ethnic minorities. Fourth, they are integrated into the ethnic minorities through intermarriage. Ethnic intermarriage and ethnic integration is also very common, such as the Hui and Han marriage, as early as the mid-7th century, a large number of Arab, Persian Muslim merchants from the sea into the Central Plains and settled in coastal commercial ports, the early 13th century, Mongolia Western expedition occupied the Islamic countries in Central Asia, the merchants and artisans in these countries were expeditionary expeditionary force, after the army entered the conquest of the Southern Song Dynasty in China, called it the Red Army, there are also some Chinese call it a return to the army, After the marriages between Muslim merchants settled in coastal commercial ports and the Han Chinese formed Hui people, as well as the people who believe in Islam in all the existing provinces in China[7]. 


\subsection{Integration of ethnic minorities}

The integration of ethnic minorities is more common. The main modes include the ethnic integration caused by conflicts, the integration of rulers by the ruled peoples and the national integration caused by migration.[7] The war between the ethnic groups will lead to defeated tribes, tribes are divided, the divided ethnic groups are likely to be integrated into other ethnic groups, such as the Huns, Xianbei, Turkic gathered in the Mongolian prairie life, however, between the various ethnic groups It has also been a war chaos, the victors to absorb a large number of other ethnic minorities, and losers will be divided into other nationalities split, by other nationalities assimilation. Because of the ethnic integration caused by migration is very common, such as the Uyghur ancestors and the Tang rulers to overthrow the Turkic Khanate, and the establishment of Northern Khanate Khanate nation, 840 years after the collapse of the Khanate, rejected the people scattered migration, which A member of the resettlement team refused to enter the nomadic area along the Great Wall and entered the Central Plains into the Han Chinese in the mid-9th century. There are mainly two types of rulers in their integration with the ruled peoples. One is the long-term integration of the rulers and the ruled to form a new nation. For example, the ancient Tuyuhui included Xianbei, Qiang, Huns, Turkic, Han and other ethnic groups after hundreds of years of national integration formed. [7]

\section{The Characteristics of Chinese History and National Integration}

It can be said that all of the long-established and populous ethnic groups have not undergone long-term and extensive integration but the integration of the Chinese nation embodies the following characteristics:

\subsection{Concentric integration}

After all, the Chinese nation has developed for thousands of years. However, no matter at any stage, the core of the various ethnic groups is dominated by the Huaxia ethnic group, followed by the Han ethnic group and the region with the Yellow River and the middle and lower reaches of the Yangtze River as its main hinterland. Before the Spring and Autumn Period, the Yi, Man, Di and Rong were merged with the Huaxia ethnic groups one after another, and Han people were formed on the basis of this. After Qin and Han dynasties, ethnic minorities such as Saibei and Western Regions invaded the Central Plains, Quantity and quality of the Chinese nation. As a result, the Han people have fused a large number of other ethnic groups in the long-term development process and gradually expanded their own scope of activities [8].

\subsection{The deep content}

Compared with the nomadic mode of production, the stability and advanced nature of agricultural production are all more prominent in the Huaxia ethnic group. Therefore, the integration of the nomadic tribes and tribal allies in the northwestern and northern parts of the Huaxia ethnic group by the Huaxia ethnic group is also justified While the tribes and nationalities in the south and southwestern regions dominated agricultural production. However, due to the restriction of natural conditions, their productivity was low, and eventually they were also integrated by the Chinese nation. Other ethnic groups that are being merged accept the advanced modes of production of the Han people and virtually accept the advanced cultures and lifestyles of the Han people. In particular, the mainstream Han has become the common ideological guidance of the Chinese nation. And the language and writing of the Han people have always been the official languages and writings of the Chinese nation. From this it can be seen that the integration of the Chinese people has a profound cultural foundation and economic foundation [9].

\subsection{The continuity of history}

The Chinese nation has over 4000 years of documented history. Although it has suffered repeated setbacks in the course of its development, the Chinese nation in general has been moving toward an increasingly powerful direction. Although the Chinese nation has not been involved in the Chinese 
territory today, whether it is the scope of activities or activity history, are rare among the nations of the world. Among the ancient civilizations in the world, the four ancient civilizations, Babylon, the ancient Indian nation, the ancient Egyptian nation and the Chinese nation, the primitive cultures of the first three were interrupted by the assimilation of foreign nations. Only the ancient Chinese culture was preserved and developed in its entirety. Although the changes of dynasties dynasties are a major feature of the development of the Chinese nation, each war and conquest of each other after the conquest of each other to absorb each other's advantages or preserved, and ultimately this wave of historical evolution formed for thousands of years Continuous chain.

\subsection{The integration of the interaction}

Although the integration of the Chinese nation is dominated by Chinese, it is not simply Chineseization. As mentioned above, the types of ethnic integration are not only the integration of ethnic minorities into the Han nationality, but also the integration of the Han into the minority nationalities or the integration of ethnic minorities [9]. The vast majority of the Chinese people are of Mongol ethnic origin. However, from south to north, there is a gradual change from east to west. For example, the northern part is of the East Asian type with the Mongol ethnic predominance in the north and the South Asian type mainly of the Dai ethnic group in the south or transitional types; while the northwestern region is a mixture of races, including Mongoloid and Europa species. It can be seen from this that the history of the Chinese nation has been deeply rooted in history and has a long history and reflects the characteristics of interactive integration.

\section{Conclusion}

In short, in the history of mankind, the various ethnic groups do not always live in peace with each other. Both ethnic groups have both communication and conflict. Therefore, ethnic relations in history are complicated. Analyzing ethnic integration can not be based on the specific position of a particular nation. But to conduct analysis and appraisal based on a more objective and comprehensive view. It is necessary to see the mutual absorption, interdependence and proximity between different ethnic groups. It is precisely the common rejection of class oppression and foreign aggression among all ethnic groups in China, which constitutes the basic contents of our ethnic relations and national integration. National integration is mainly cultural integration. In times of war, the larger the scale of war, the greater the national integration. The natural integration and active integration are the mainstream of national integration in Chinese history. As a multi-ethnic country, our country has undergone a complicated development from small to large and from split to unity. Among the reasons for promoting the unification of the Chinese nation, ethnic integration is an important reason. It is precisely because of the continuous integration of ethnic groups. The relations between the various nationalities in our country have enhanced national cohesion and the historical and cultural identity between different ethnic groups has also been constantly expanded. To some extent, integration is the eternal theme throughout the process of the nation's emergence, development and demise.

\section{References}

[1] Wu Songdi. Origin of Hakka Southern Song Dynasty [J]. Fudan Journal (Social Science Edition), 1995 (5): 6

[2] Wang Daliang. Discussion on the relationship between Hakka and the Central Plains [J]. Jiaying University, 1998 (1): 110-115

[3] Shi Chaojiang. Miao migration in the history of the five waves [J]. Guizhou Ethnic Studies .1995 (1): 120-128

[4] He Xingliang. Characteristics and types of national integration in Chinese history [J]. Journal of South University for Nationalities (Humanities and Social Sciences), 2010,30 (2): 35-43 
[5] Chen Ling, Liu Yun good. On the "Native" Literature of the Mobei Literature District [J]. The Research of Ethnic Literature, 2011 (6): 49-56

[6] Ni Fangliu. The origin and disappearance of human martyrdom [J]. Chinese Legend, 2010 (5): 29-31

[7] Song Juan, Geng Tiehua. A preliminary study on the sacrificial burial practices of Goguryeo [J]. Northeast Relics, 2009 (3): 64-66

[8] Jing Chenshu. Murong Xianbei funeral customs test [J]. Humanities Magazine, 2005 (3): 126-132

[9] Cai Fenglin. On the "Four-person System" in Yuan Dynasty - Also on Some Characteristics of Political Culture in Yuan Dynasty [J]. Journal of Inner Mongolia Normal University (Philosophy and Social Sciences), 2008 (3): 13-20

[10] Li Chong. (Mongolian) Yuan a hundred years national policy review [J]. Xinzhou Teachers College, 2007 (6): 79-83

[11] Peng Jianying. The types, characteristics and main guiding ideology of ethnic policies in Yuan Dynasty [J]. Northeast History, 1996 (2): 82-88 